\title{
MODELOS Y PROBLEMAS EN EL ESTUDIO DE LA CIRCULACIÓN DE LA TEORÍA LITERARIA: Pierre Bourdieu (1989), Pascale Casanova
} (1999) Y EL SECUESTRO DEL BARROCO* MODELS AND PROBLEMS IN THE STUDY OF THE CIRCULATION OF LITERARY THEORY: PierRe Bourdieu (1989), Pascale Casanova (1999) AND THE KIDNAPPING OF THE BAROQUE Max Hidalgo Nácher ORCID 0000-0001-8587-8995

Universidade de Barcelona, Barcelona, Espanha

\section{Resumen}

Este artículo repasa críticamente algunos de los modelos historiográficos universalistas más destacados en el estudio de la circulación de la literatura y de la teoría literaria. La conferencia "Les conditions sociales de la circulation internationale des idées" (1989), de Pierre Bourdieu coincide cronológicamente con la publicación de $O$ sequestro do barroco na formação da literatura brasileira: o caso Gregório de Matos, en la cual Haroldo de Campos proponía una lectura crítica de la Formação da literatura brasileira (1959), de Antonio Candido. Desde esas coordenadas, es posible aislar en la literatura mundial -a través de la lectura de La République mondiale des Lettres (1999), de Pascale Casanova- otro "secuestro del Barroco" que hay que retrotraer hasta mucho más atrás y que se hace visible gracias a trabajos como el llevado a cabo por Leyla Perrone-Moisés y Emir Rodríguez Monegal en Lautréamont austral (1984). Esas obras no son aquí traídas en sí mismas, sino en tanto que siguen repitiéndose o interpelándonos en el presente, pues la ascendencia de modelos y prácticas monológicas se transmiten de las historias nacionales a las historias mundiales de la literatura, y sigue siendo actuante hoy en día.

Palabras clave: Antonio Candido, Haroldo de Campos, circulación de la teoría literaria, World Literature, barroco.

\footnotetext{
*Este artículo es la segunda parte del tema que discuto en: "Modelos y problemas en el estudio de la circulación de la teoría literaria (I): Candido (1959), Haroldo de Campos (1989) y el secuestro del Barroco", publicado en la revista Landa, v. 7, n. 2, 2019. Disponible en: <https://repositorio.ufsc.br/ handle/123456789/199544>.
} 
Abstract

This article provides an overview of some of the most prominent universalist historiographical models in the study of the circulation of literature and literary theory. Pierre Bourdieu's conference "Les conditions sociales de la circulation international des idées" (1989) coincides chronologically with Haroldo do Campos' O sequestro do barroco na formação da literature brasileira: o caso de Gregório de Matos. In this work, Campos put forward a critical reading of Antonio Candido's Formação da literature brasileira (1959). These coordinates allow the isolation of another "kidnapping of the Baroque" in world literature -through the reading of Pascale Casanova's La République mondiale des Lettres (1999). This "kidnapping" must be traced back to a much earlier time and it has been rendered visible in works such as Leyla Perrone-Moisés and Emir Rodríguez Monegal's Lautréamont austral (1984). These works are not examined here in themselves, but insofar they keep repeating themselves and continue to question the present. The monological models and practices are transmitted from national histories to world or universal histories of literature and are still currently in use.

Keywords: Antonio Candido, Haroldo de Campos, circulation of literary theory, World Literature; baroque.

\section{Resumo}

Este artigo examina alguns dos modelos historiográficos mais destacados pertencentes a uma tradição universalista do comparatismo no estudo da circulação da literatura e da teoria literária. A conferência "Les conditions sociales de la circulation internationale des idées" (1989) de Pierre Bourdieu coincide cronologicamente com a publicação do Sequestro do barroco na formação da literatura brasileira: o caso Gregório de Matos, onde Haroldo de Campos propunha uma leitura crítica da Formação da literatura brasileira (1959), de Antonio Candido. A partir dessas coordenadas, é possível isolar na literatura mundial mediante a leitura da République mondiale des Lettres (1999) de Pascale Casanovaum outro "sequestro do Barroco" que podemos fazer recuar até muito antes e que se faz visível, por contraste, através de trabalhos como o empreendido por Leyla Perrone-Moisés e Emir Rodríguez Monegal em Lautréamont austral (1984). Essas obras são aqui estudadas porque ainda se repetem ou nos interpelam nas práticas e discursos críticos do presente, já que a ascendência de modelos e práticas monológicas passa das histórias nacionais às histórias mundiais ou universais da literatura, e segue sendo atuante na atualidade.

Palavras chaves: Antonio Candido, Haroldo de Campos, circulaçáo da teoria literária, World Literature; barroco. 
Haroldo de Campos daba a la prensa en 1989 su lectura de Candido, O sequestro do barroco na formação da literature brasileira: o caso de Gregório de Matos (HIDALGO NÁCHER, 2019). El mismo año en que se publicaba ese libro en Brasil, pocos días antes de la caída del muro de Berlín -concretamente, el 30 de octubre-, un sociólogo francés impartía una conferencia en Friburgo en la que, declarándose a favor de la internacionalización de la vida intelectual, presentaba "un programme pour une science des relations internationales en matière de culture" (BOURDIEU, 2002a, p. 3) que tematizaba su objeto a partir de los malentendidos, pues "les échanges internationaux sont soumis à un certain nombre de facteurs structuraux qui sont générateurs de malentendus" (p. 4) $)^{1}$. Se trataba, claro está, de Pierre Bourdieu y de su ya célebre conferencia "Les conditions sociales de la circulation internationale des idées".

Es ya un lugar común remitir, en los estudios sobre circulación, a esa conferencia de Bourdieu, republicada en Francia justo después de su muerte, como a un lugar de autoridad. Su gesto inaugural supone un desplazamiento: el título de la conferencia remitía a las ideas, pero el contenido a los textos; unos textos, decía Bourdieu, que circulan internacionalmente sin su contexto, lo que provoca equívocos. Sometidos a las operaciones de selección, marcaje y lectura (p. 4), habría, pues, que estudiar la circulación de los textos en la tensión entre contexto de origen y contexto de llegada.

Esa propuesta, de base científica, se montaba sobre el corpus y la querella franco-alemana. Bourdieu heredaba un modelo ilustrado, basado en la razón y en la comunicación, y pensaba la circulación desde un modelo franco-alemán, desde el romanticismo hasta los años ochenta, a partir de un rasgo típico de esa querella: el equívoco. El sueño científico de Bourdieu era eminentemente francés, igual que su promesa o sueño de la razón: podríamos llegar a superar los malentendidos a través de la ciencia.

Esa conferencia de Bourdieu, de la que nos separan ya treinta años, establecía algunas condiciones de posibilidad para empezar a pensar el juego de la circulación como producción. Ahora bien, al tiempo que las sentaba, instauraba uno de los cierres de ese mismo discurso científico: una teoría ilustrada de la comunicación. Bourdieu creía que el equívoco podía ser atenuado y trabajaba para ello a través de la objetivación de los objetivadores ${ }^{2}$, minimizando las contingencias del sentido.

1 "Le fait que les textes circulent sans leur contexte [...] est générateur de formidables malentendus" (BOURDIEU, 2002a, p. 4).

2 Sobre las transformaciones del problema de la reflexividad en la obra de Bourdieu puede consultarse VÁZQUEZ GARCÍA, 2006. 
Cabe destacar, en este sentido, dos tendencias que es posible aislar en el seno de la propia obra de Bourdieu en relación con la literatura. Una consiste en tomar la literatura como pensamiento, de modo que se hace posible ir a buscar en ella un saber específico, una mirada nueva sobre lo social (tal es la enseñanza que extrae de la lectura de Al faro de Virginia Woolf en $\mathrm{La}$ dominación masculina [BOURDIEU, 2002b, p. 56 y 112]); la otra, en reducir la literatura a un epifenómeno de lo social (a Bourdieu le gustaba recordar a aquel Durkheim que decía "La sociedad es Dios" [BOURDIEU, 2002c, p. 56]). Así ocurre, por ejemplo, cuando leemos en la entrevista "Todo es social":

Hay una especie de masoquismo en los críticos que ven el texto como un fetiche: prefieren buscar las cosas exclusivamente en la escritura, es decir, allí donde a menudo es especialmente difícil leerlas, mientras que podemos encontrar perfectamente la misma información de forma más clara en otra parte, por ejemplo en el ámbito de las prácticas (BOURDIEU, 2014, p. 64).

Ese vaivén teórico de Bourdieu -que muestra cómo concibe la literatura en continuidad con un espacio social que es él mismo continuo ${ }^{3}$ - prefigura el espacio de recepción en el que, todavía hoy, es leído e incorporado desde los más variados contextos, oscilando entre dos modos de apropiación que convierten su teoría bien en una herramienta crítica que no deja de interrogarse constantemente por la tensión que une y separa las diversas series de lo social, bien en un nuevo positivismo.

Esa vía literaria -que algunos autores como Sergio Miceli, principal introductor y continuador de Bourdieu en Brasil, ven como en último término mágica y religiosa ${ }^{4}$ - puede permitirnos entender esa circulación desde otro ángulo para pensar la junción entre las condiciones sociales de recepción y la propia circulación internacional de los textos. Ese diferendo entre los textos y su sentido, entre la estructura social y la lectura, que la mayoría de los autores vive como una oposición en la que habría que tomar partido por un

3 Esta concepción del lugar social de la literatura coincide con la idea de objetividad de Schwarz: "Os problemas estéticos têm objetividade, engendrada pela História intra e extra-artística. Ao enfrentá-los, ainda que sob a feição depurada de uma equação formal, o escritor trabalha sobre um substrato que excede a literatura, substrato ao qual as soluçōes alcançadas devem a força e a felicidade eventuais. As questôes de forma não se reduzem a questôes de linguagem, ou são questôes de linguagem só na medida em que estas últimas vieram a implicar outras do domínio prático" (SCHWARZ, 1990, p. 224-225).

4 Esta atribución se aprecia en la adjetivación y el campo semántico que Miceli convoca para referirse a los críticos de Sur, que usarían -haciendo gala de un "esoterismo letrado"- de un "dispositivo hiperintelectualista" y "lentes especiais de revelaçăo" (2018, p. 94). Según Miceli, "Borges incensava o ego do leitor ao the conceder o privilégio de sentir-se dotado do cabedal indispensável ao desfrute de iguarias; ato contínuo, ele nivelou o status do leitor ao do escritor, como que turvando a agência autoral. Primus inter pares, o Borges leitor concebeu a confraria dos convertidos à nova profecia. A inserção a mençōes cifradas a personagens e a lugares do imaginário classista, bem como de idiossincrasias do linguajar portenho, foi se convertendo em matéria de adivinhação para a crítica literária" (p. 92). 
término, constituye el espacio de posibles (la estructura) y la posibilidad de lo imposible (el acontecimiento) que se ponen en juego en la lectura. Negar la ascendencia de lo social (en la que se incluyen dispositivos, prácticas y discursos) es tan vano como empeñarse en omitir la contingencia de la lectura en lo que tiene de producción y de puesta en movimiento, en último término imprevisible, de las series. No se trataría, pues, de tomar partido por una lectura interna o por una lectura externa-lo que sería interrumpir el circuito que comunica el texto con lo social y que interrumpe y recomienza una y otra vez esa comunicación-, por un posible filosófico o un posible histórico ${ }^{5}$, sino de incorporar y articular niveles de análisis a partir de problemáticas específicas. Esta juntura, sin embargo, ha tendido a quedar negligida por las principales contraposiciones que han estructurado hasta el día de hoy estos estudios, las cuales obturan la posibilidad de pensar el acontecimiento y siguen repitiendo en la práctica una oposición tajante entre el texto y lo social, fijándose muchas veces más en lo que los textos críticos dicen sobre ellos mismos (y sobre los otros textos) que en lo que efectivamente hacen (PUCHEU, 2012, p. 92-93).

Lo que dificulta la comunicación de las dos partes en conflicto es una diferente concepción de lo literario y de lo social. Cabría afirmar, en ese sentido, que los defensores del segundo tipo de lectura han incorporado una lección socio-histórica, pero sin problematizar lo específico literario; mientras que los defensores del primero han descubierto los poderes productivos de la literatura, pero no han extraído de ello sus consecuencias histórico-sociales. Ese "impasse quase secular na crítica brasileira" del que hablaba Schwarz en 1989 (p. 17) es, precisamente, uno de los elementos que estructura la toma de posiciones de la crítica brasileña actual ${ }^{6}$, y sigue repitiéndose hoy, con

5 Escribe Miguel Dalmaroni: "Habría, entre tantos, un posible histórico de la crítica, que indaga lo que sucedió y, por supuesto, nos permite interrogarnos sobre su significado para nuestro presente, pero no solo para nuestro presente. Habría, en cambio, entre tantos, un posible filosófico de la crítica, que compone no lo que sucedió sino lo que se muestra significativo o revelador para nosotros" (2005, p. 8). A lo que añade: "Por supuesto que, una vez trazada la distinción, conviene notar que entre los mejores trabajos críticos están aquellos que toman a su cargo los desafíos de esos dos posibles a la vez, que pasan de uno al otro no porque los confundan sino porque conocen y prueban su vinculación consecuente (aunque no necesariamente secuencial). No habría, en rigor, historia crítica de la literatura sin esa confluencia” (p. 11).

6 Aunque la matiza justo a continuación, Célia Pedrosa refiere "a polarização entre duas formas de definição de nosso pensamento acadêmico a partir da metade do século XX, que repóem em termos específicos uma tradicional luta pela hegemonia cultural no interior do eixo Rio de Janeiro-São Paulo. / De um lado, teríamos a crítica devedora do pensamento formulado pela Universidade de Sáo Paulo a partir de 1940 pensamento esse voltado para a problematizaçáo das ideologias ligadas ao processo de construção do Estado nacional, e para uma análise da dependência cultural de cunho sócio-econômico, com nítida inspiração marxista, preocupaçōes às quais se soma a de definir uma tradição moderna de literatura brasileira a partir de uma constante releitura de obras já canônicas, cujos parâmetros se limitam, por um lado, pela narrativa machadiana, e, por outro, pela produçâo dos autores modernistas "verdadeiramente" modernos. De outro lado, teríamos a crítica cujos agentes se inserem em universidades do Rio de Janeiro e evidenciam um débito em relação a diversos modos de reflexão estruturalista e pós-estruturalista, basicamente francesa, 
modulaciones, tanto en los estudios sobre este corpus ${ }^{7}$ como en polémicas como la protagonizada a comienzos del siglo XXI, como una repetición del pasado que estudian, por Heloisa Pontes (1998) y Leda Tenório da Motta (2002, especialmente p. 43-88).

La literatura mundial y la República mundial de las Letras (1999)

Los primeros en no registrar la peculiaridad y abundancia de la circulación de nuestros discursos académicos, críticos y teóricos somos nosotros.

CATELLI, 2018, p. 184

El réquiem que se ha entonado por las historias de la literatura no debería ser demasiado compungido si no fuera por la siguiente salvedad: cada vez que se piensa en las relaciones entre literatura e historia, los esquemas, los conceptos y aun los métodos de aquellas historias retornan como si un derecho inmemorial las asistiera. Los conceptos de 'época' y 'culminación', por ejemplo, asi como la vinculación determinante de la literatura con las formaciones nacionales, llegan hasta nosotros como si no hubiera otros instrumentos disponibles.

AGUILAR, 2003, p. 381

Más allá de las historias nacionales de la literatura, en las que podría tratar de clausurarse la anterior confrontación, en los últimos años ha ido adquiriendo importancia un estudio de área que pretende prolongar y desplazar al mismo tiempo a la antigua literatura comparada: la World Literature o literatura mundial. Los textos fundadores del nuevo campo son La République mondiale des Lettres, de Pascale Casanova (1999); "Conjectures on World Literature" (2000) y "More conjectures" (2003), de Franco Moretti; y What is World Literature, de David Damrosch (2003). Volver sobre esos estudios permite formular un problema básico del estudio de la circulación teórica y literaria en general ligado a la construcción de sus objetos teóricos y a la visibilización e invisibilización de los mismos. Cabe añadir que la World Literature ha dedicado a las literaturas latinoamericanas una atención menor ${ }^{8}$ y que su interés por la literatura raramente ha sido extensible a la circulación teórica que la redobla y acompaña. En este sentido, y referidas a la crítica y

ao invés da filiação unilinear a uma doxa entendida como autenticamente brasileira e voltada para nossa verdadeira realidade. É o que ocorre com Silviano Santiago, e sua atualização do desconstrucionismo derridiano, e Luiz Costa Lima, que transita da antropologia estrutural de Claude Lévi-Strauss às teorias da recepção da Escola de Kontanz" (PEDROSA, 2001, pp. 239-240).

7 Como muestra de este tipo de lecturas, cabe remitir a CHIAPPINI, 2018.

8 Constituye una excepción en este panorama el monográfico editado por PUXAN-OLIVA y MIRIZIO, 2017. 
a la teoría, son pertinentes las diversas cronologías traductoras trazadas por Catelli-las cuales configuran constelaciones teóricas siempre singulares- y su referencia al comparatismo "implícito" y "espectral" (2018, p. 181) argentino:

Hacia 1958 el comparatismo parecía fosilizarse, al menos donde se practicaba con conciencia de hacerlo: parte de Europa y de Estados Unidos. Porque hubo otro comparatismo inadvertido y que es casi como la respiración de la lectura: se desarrolló en otras latitudes, las nuestras, y no formó un corpus académico. El que ha pasado a la historia de la disciplina es únicamente el primero, el fósil visible de 1958 ” (2015, p. 35).

La République mundial des Lettres no es ajena a estos problemas?. El trabajo de Casanova tiene el valor innegable de proponer el estudio de las relaciones literarias internacionales a través de un sistema literario articulado por las nociones de capital simbólico. Si aquí nos referimos a ese libro se debe a que constituye un caso especialmente relevante en el estudio de la literatura mundial que, por su sistematicidad y su carácter enciclopédico, permite plantear problemas que tienden a quedar velados en otros estudios. $\mathrm{Su}$ principal interés radica en que construye un modelo uni-versal aplicable para pensar un espacio literario internacional unificado y organizado en función del prestigio o capital simbólico. En ese espacio, los países periféricos tienen una deuda contraída con los centrales, la cual -como ocurre con la deuda externa- es renovada en cada nueva transacción pues, como afirma Schwarz, "também nas Letras a dívida externa é inevitável" (1977, p. 47). Como ha mostrado Santiago a propósito de Lévi-Strauss, ese modelo espacio-temporal puede reducirse a la paradoja de Aquiles y la tortuga descrita por Zenón (2005, p. 22-24, 27 y 44). Tal como Aquiles parece que ganará a la tortuga, Latinoamérica parece más joven y actualizada que Europa. Sin embargo, y por eso mismo, "recua-se no espaço o mais jovem e mais veloz para que o mais velho e mais lento avance no tempo e ganhe a dianteira" (p. 27). Europa parte de una ventaja: su antigüedad ${ }^{10}$. Y Latinoamérica nunca dará caza a Europa, pues no es pensada más que como una función de ella ${ }^{11}$.

Entre Bourdieu y Casanova -quien parecería desarrollar las ideas de Bourdieu aplicadas a la literatura en un espacio internacional- no hay

9 El libro ha cosechado un gran éxito, el cual no ha dejado de ir acompañado de muchas críticas. Puede consultarse a este respecto GRAMUGLIO, 2013, p. 390.

10 "La ley temporal del universo literario puede enunciarse así: hay que ser antiguo para tener alguna posibilidad de ser moderno o de decretar la modernidad. Es preciso tener un largo pasado nacional para aspirar a la existencia literaria plenamente reconocida en el presente" (CASANOVA, 2001, p. 125).

11 Puede verse, en este punto, la "exceção superior" que constituye Nueva York, ciudad que "se torna modelo para a avaliaçâo das cidades latino-americanas" (ibid.., p. 36), en el planteamiento de Lévi-Strauss (SANTIAGO, 2005, p. 33). 
malentendidos. Y, sin embargo, la vía de Bourdieu -el estudio material de la cultura- queda muy lejos de la perspectiva de Casanova, quien trabaja, dada la amplitud de su objeto de estudio, con materiales de segunda mano. De ese modo, ahí se cruza un modelo teórico francés con relatos de las más diversas historias nacionales de la literatura y una práctica periodística que privilegia las voces de los actores y, por lo tanto, lo que Analía Gerbaudo llama los "cuentos" $(2017,2018)$. Este procedimiento, asociado a una cierta imaginación geográfica, produce cortocircuitos, que tienden a adquirir la forma de lagunas o de errores historiográficos, tal como ocurre con el caso de William Faulkner e Hispanoamérica (CATELLI, 2009, p. 37). Según Casanova, el escritor español Juan Benet fue el descubridor de Faulkner para las literaturas en lengua española en una fecha tan tardía como 1961. Faulkner, conforme a ese relato, habría sido descubierto primero por los españoles y solo en un segundo momento incorporado por los latinoamericanos. Ese error muestra un importante desconocimiento histórico - pero tal es el riesgo, a fin de cuentas, de cualquier universalismo ${ }^{12}-$, pues Faulkner fue incorporado en España después de una larga tradición de lecturas y usos americanos ${ }^{13}$. Borges reseñó tres libros de Faulkner ya en los años treinta, y tradujo The Wild Palms en 1940, inaugurando una tradición

12 Escribe Catelli con relación a la famosa frase de Borges en "El escritor argentino y la tradición" que afirma erróneamente, remitiendo a Gibbon, que no hay camellos en el Corán: "Leída ahora, en efecto, la afirmación acerca de la ausencia de camellos parece menos el motor eficaz de un razonamiento que un punto ciego de este texto. Casi podría decirse que es su falla: hasta produce cierta incomodidad [...]. Así, el punto ciego puede ser pensado como recordatorio ejemplar de la insuficiencia de toda pretensión de verdadera universalidad. No sólo nuestra, sino de cualquiera: Borges respecto de los camellos de Mahoma, o los especialistas norteamericanos de los estudios culturales respecto, por ejemplo, de Latinoamérica o Hispanoamérica, conjuntos a los que se aplica un esquema de subalternidad que presupone unos vínculos de ida y vuelta, entre metrópolis y colonia, característicos de los imperios francés y sobre todo inglés del siglo XIX y en absoluto adecuados al complejo y multifacético devenir de la modernidad en nuestras Américas, a partir de las independencias alcanzadas, en su mayor parte, a principios del siglo XIX" (2003, p. 32).

13 Escribe Casanova: "El escritor español Juan Benet es sin disputa uno de los primeros en haberlo comprendido, pero tras él, todos los escritores del 'sur', en el sentido amplio, de las Antillas a Portugal, pasando por Sudamérica o África, han reconocido a Faulkner como el que les ha revelado una posibilidad de acceder al presente de la literatura sin por ello renegar en absoluto del legado cultural propio" (2001, p. 434). Escribe Catelli, comentando ese pasaje: "¿«Uno de los primeros en haberlo comprendido»? ¿"Tras él»? Nunca llegarás a nada es de 1961; casi treinta años antes Borges había reseñado en Buenos Aires Absalom, Absalom (en 1937), The Unvanquished (en 1938) y The Wild Palms (en 1939), que un año más tarde apareció en su traducción; en 1955 Juan Rulfo había publicado Pedro Páramo; en 1950 Juan Carlos Onetti -cuya primera novela es de 1938- había dado a conocer La vida breve, donde inauguró el ciclo de Santa María. Y en 1962, en la revista Marcha de Montevideo, había aparecido el Réquiem por Faulkner del propio Onetti, después reunido en libro con otros ensayos. El equívoco se deriva de una falta de información: Casanova no sabe que la traducción de Las palmeras salvajes de Borges es de 1940 y que Benet la prologó en 1970, cuando apareció en Espańa, el mismo ańo del debate sobre el realismo que cierra el volumen de Taurus. Casanova por tanto no sabe que en 1970 Benet ya había diseńado dos combates: el combate con el realismo y el combate con Borges por la apropiación de Faulkner. En 1986 la pugna contra el realismo de su propia generación estaba ganada; pero era mucho más problemática la disputa por el sitial internacional de la literatura en castellano" (CATELLI, 2009, p. 39). 
faulkneriana que sólo tardíamente fue incorporada a una España que en 1939 entraba, con la victoria militar de Franco, en un largo periodo de indigencia y autarquía.

En otro orden de cosas, se trata de un relato histórico construido con un patrón unitario y representativo (monológico): una única modernidad, una única vanguardia; un único autor y movimiento por país, legítimos representantes de dicha vanguardia, relativa siempre al "meridiano de Greenwich" que marca los husos horarios de la modernidad (CASANOVA, 2001, p. 122-142). La postulación de relaciones estables y unidireccionales entre campos literarios, la omisión de los contactos entre las periferias y la instauración de un único patrón de medida de la modernidad (en este caso, el metro parisino) descartan las múltiples temporalidades de lo moderno. Por imperativo de la Unidad, a la que ya se refirió Silviano Santiago en "O entrelugar do discurso latino-americano”, ha de haber en cada nación UN único autor en tanto que representante de LA modernidad. Ese esquema da lugar, cronológicamente, a linajes (en Irlanda, Beckett sigue a Joyce). Así, se borran las tensiones internas y la pregunta problemática por la contemporaneidad (AGAMBEN, 2011). De ese modo, se aplanan y unifican problemáticas que, desde otro punto de vista o desde otro espacio enunciativo, adquieren dimensiones muy diferentes.

Los trabajos sobre literatura mundial ponen en evidencia uno de los problemas cruciales en los estudios sobre circulación: la importancia de los centros geográficos de producción y de la construcción de la mirada a partir de ellos. La asimetría existente entre los diversos centros de producción se revela en los flujos de traducciones (SAPIRO, 2010; HEILBRON, 1999; VENUTI, 1998), en los índices bibliográficos (CATELLI, 2015, p. 41) y, de modo más sutil, en la visibilidad de los objetos de estudio y de sus posibles relaciones (CATELLI, 2018) ${ }^{14}$. La idea común según la cual la teoría es lo que se hace en las metrópolis y la crítica es lo que hacemos nosotros ${ }^{15}$ responde a un mismo estado de cosas. Ahora bien, estudios como los de Casanova

14 Antelo se propone en su libro Maria com Marcel Duchamp nos trópicos "reconstruir o sistema de saber de um conjunto heterogêneo, quando não abertamente miscelâneo, de objetos culturais que guarda estreita relação com a cultura latino-americana", mostrando "de que modo a cultura periférica incide na elaboração da teoria modernista da arte e da sensibilidade no Ocidente e, ao mesmo tempo, de que modo se processou uma sutil obliteração dessa história cultural que, em nome da autonomia e mesmo reivindicando a diferença, solapa certa filigrana cultural que, para vir à tona, requer a laboriosa reconstrução de uma anamnese demorada” (2010, p. 9-10).

15 "En la Argentina, la teoría y la crítica literaria han estado unidas por un lazo matrimonial. Es más, un matrimonio por iglesia. La crítica es la amante y es criolla, la teoría es la amada (tiene ascendientes rusos, pero es bastante francesa, algo alemana, algo británica; digamos con pasaporte de la Comunidad Europea, incluso después de haber ensayado un par de mudanzas aquende el Atlántico) [...]. El pensamiento escrito sobre literatura en la Argentina es crítica literaria argentina, no teoría” (DALMARONI, 2018, p. 102). 
tienden a reproducir en el plano historiográfico una mirada que redobla ese esquema, contribuyendo a invisibilizar todo aquello que no encaja en él.

\section{Cantos paralelos y cantos de ida y vuelta}

La República mundial de las Letras tiene el mérito de tematizar, a nivel general, un espacio literario mundial basado en relaciones desiguales entre centro y periferia. De ese modo, construye un espacio inteligible, pero solo a condición de borrar o colocar en segundo plano aquello que no se deja reducir al modelo que lo funda. En primer lugar, el modelo hace difícil pensar las relaciones de inversión de flujos entre centros y periferias y los procesos de desestabilización que, debido a invasiones bárbaras -por todas partes, los bárbaros ${ }^{16}$-, pueden producirse en los grandes centros literarios e intelectuales (EVEN-ZOHAR, 1999). Un caso célebre de la irrupción de esas heterolalias fue el panfleto Critique et vérité (1966), en el que Roland Barthes acusaba a la vieja crítica francesa que, a fin de cuentas, seguía detentando la normatividad literaria intramuros de la universidad, de hablar una jerga heredera de los siglos del neoclasicismo y del positivismo y reconocía -si el francés era esa jerga- no hablar francés, sino chino. A lo que añadía: “¿Reprocharían a un chino (dado que la nueva crítica les parece una lengua extranjera) hacer faltas de ortografía en francés, cuando habla chino?" 17.

En segundo lugar, las relaciones entre "centros" y "periferias" son complejas y de múltiples sentidos. Roman Jakobson contribuyó a la socialización de Haroldo y de Décio Pignatari en el contexto de la Asociación Internacional de Semiótica desde 1969; pero, al mismo tiempo, Haroldo fue el introductor de Jakobson en el mercado editorial brasileńo y uno de sus principales mediadores en su circulación mexicana, al ponerlo en

$16 \mathrm{El} \mathrm{tema} \mathrm{de} \mathrm{los} \mathrm{bárbaros} \mathrm{es} \mathrm{recurrente} \mathrm{en} \mathrm{las} \mathrm{referencias} \mathrm{a} \mathrm{la} \mathrm{renovación} \mathrm{teórica} \mathrm{de} \mathrm{finales} \mathrm{de} \mathrm{los} \mathrm{sesenta}$ y principios de los setenta. Santiago arranca su artículo refiriéndose, por mediación de Montaigne, a unos bárbaros que no parecen tales. Haroldo, por su parte, presenta a los escritores latinoamericanos como "vorazes bárbaros alexandrinos" (1981a, p. 253-254). Enric Sullà arranca su nota crítica sobre la renovación teórica en la España de finales de los sesenta y principios de los setenta, titulada "Esperant els bàrbars", refiriendo al poema de Kavafis: “Títol i citació s'expliquen perquè m’ha convingut que els bàrbars del poema fossin no tan sols els estructuralistes sinó tots els pensadors francesos (i estrangers en general) que són esperats pels ciutadans d'un país sufocat, perquè l'han volgut aillar fent-li creure que no li cal res de fora perquè ja ho té tot, un país, doncs, la gent més inquieta del qual espera paradoxalment que els forasters li resoldran els problemes que no ha sabut o no ha pogut resoldre. Si al poema de Cavafis els bàrbars que solucionaran la decadència acaba que no arriben, a l'Espanya i la Catalunya dels últims anys dels seixanta sí que hi van arribar, d'una manera indirecta és clar, però hi van arribar, i, obliquament, van contribuir a remoure les aigües somortes de la universitat, del pensament, de la cultura" (SULLÀ, 2015, p. 25). En el caso de Sullà, los bárbaros son los franceses (y, en general, el pensamiento contemporáneo); en Haroldo de Campos, en cambio, los bárbaros son los propios escritores latinoamericanos. En todos esos casos los bárbaros aparecen connotados positivamente.

17 "Reprocheriez-vous à un Chinois (puisque la nouvelle critique vous paraît une langue étrange) de faire des fautes de français, lorsqu'il parle chinois ?” (BARTHES, 1966, p. 779). 
contacto con Paz y mediar activamente en la publicación de algunos de sus textos en dicho país (HIDALGO NÁCHER 2019). Algo similar aconteció entre Paz y los jóvenes Pere Gimferrer y Julián Ríos en 1966: Paz reconoció como presentes promesas de futuro a los jóvenes escritores españoles que lo reconocían como maestro e introducían su obra en un país que, hasta ese momento, no le había reconocido y cuya poesía, hasta entonces, era "inactual por ser una poesía pasada"18.

Por otro lado, Michel Butor afirmaba que su descubrimiento de la modernidad de Mallarmé -y, por lo tanto, de aquello que de él vivificaría su obra- no le llegó por las lecturas francesas, sino por la mediación del concretismo brasileño ${ }^{19}$. Relaciones como estas, que no son ni puntuales ni meramente personales, son borradas de modo sistemático tanto por las historias nacionales de la literatura como por las perspectivas al uso sobre la literatura mundial, y solo el trabajo arqueológico y archivístico, y la atención por el detalle, consigue alumbrarlas de nuevo ${ }^{20}$. En ese sentido, Moretti, otro de los fundadores de la World Literature -campo cuya producción, no por casualidad, es casi exclusivamente en lengua inglesa-, sostenía provocativamente en "Conjectures on World Literature" (2000) el siguiente dilema: o historia nacional o comparatismo ${ }^{21}$. Esa contraposición, sin embargo,

18 "Arde el mar fue inactual en España porque usted escribió un libro de poesía contemporánea y con un lenguaje de nuestros días, hacia adelante, en tanto que la poesía de la Espańa actual es inactual por ser una poesía pasada [...]. Los poetas contemporáneos en todo el mundo -excepto en Espańa, en donde el realismo descriptivo, nostálgico y didáctico sigue imperando como si viviésemos a finales del siglo XIXestán fascinados por las relaciones entre realidad y lenguaje, por el carácter fantasmal de la primera, por los descubrimientos de la lingüística y la antropología, por el erotismo, por la relación entre las drogas y la psiquis y, en fin, por construir o destruir el lenguaje. Pues lo que está en juego no es la realidad sino el lenguaje" (PAZ, 1999, p. 21). Continua en la siguiente carta: "Mi crítica a gran parte de la poesía española contemporánea es una crítica de orden lingüístico-poético. Me parece demasiado subjetiva: más hecha de intenciones y declaraciones que de poemas. Ese subjetivismo la vuelve verbosa y sentimental, imprecisa y sin rigor" (27 de mayo de 1967, p. 23). Y sigue: "El poeta español cree todavía que el lenguaje le pertenece. Por eso lo usa, a veces con descuido, como si fuese un bien personal. Sospecho que la poesía española contemporánea no se ha planteado con entero radicalismo esto del lenguaje. Es lástima porque éste es el tema de la poesía moderna, lo que la distingue de las otras épocas [...]: no es el hombre el que constituye al lenguaje sino éste al hombre” (p. 23-24).

19 "Alors que certains représentants brillants de la conscience littéraire française traditionnelle (Valéry, Blanchot) se sont efforcés d'interpréter les audaces du Coup de dés comme une façon de nier l'aspect physique du livre par lui-même, les Brésiliens, comme un Claudel avant eux, si merveilleusement parfois sensible au changement, ont su en recevoir l'évidence sauvage" (BUTOR, 2008, p. 467).

20 Sobre el valor del detalle, cf. el análisis sobre Maria com Marcel. Duchamp nos trópicos, de Raúl Antelo (COTA, 2012, p. 153-157).

21 "This, then, is the basis for the division of labour between national and world literature: national literature, for people who see trees; world literature, for people who see waves. Division of labour . . . and challenge; because both metaphors work, yes, but that doesn't mean that they work equally well. The products of cultural history are always composite ones: but which is the dominant mechanism in their composition? The internal, or the external one? The nation or the world? The tree or the wave? There is no way to settle this controversy once and for all—fortunately: because comparatists need controversy. They 
no es tan tajante como se querría, pues no podemos olvidar que, más allá de tres y waves, tanto Moretti como el comparatismo trabajan con materiales, relatos y conceptos construidos, en gran parte, por las historias nacionales de la literatura, de modo que la historia de las historias nacionales permea los estudios críticos comparatistas.

Los efectos de esas historias nacionales de la literatura -que, en España y por indicar un par de casos, hacen sumamente difícil leer las obras de autores como José Bergamín, considerado por Agamben como uno de "sus maestros"22, o Julián Ríos (HIDALGO NÁCHER, 2014a, 2014b, 2018)no desaparecen con su crítica nominal. Un caso de su persistencia se ve precisamente en los trabajos de Moretti y Casanova. Para ella, el juego literario es, siguiendo a Bourdieu y como comentábamos antes, una lucha por el prestigio o capital simbólico del cual sólo se apropian las obras que, creando una distancia estética con relación a la literatura ya existente, son fundadoras de la contemporaneidad. Su concepción de la literatura es muy próxima a la idea de literariedad de Jakobson (CASANOVA, 2001, p. 32) y a la lógica de la revolución permanente de las vanguardias (p. 122-142). Según esa definición, podríamos pensar que Haroldo sería una pieza clave en el Brasil de la segunda mitad del siglo XX pues, más allá de sus contactos personales con Jakobson, Derrida y Eco, entre muchos otros, y de su cosmopolitismo militante, Haroldo incorpora a su obra poética, crítica y de traducción esos postulados transformadores. Ahora bien, aquí se percibe un desfase entre la teoría y la empiria pues, en el mapa de las vanguardias que fornece Casanova, en la segunda mitad del siglo XX solo aparece, entre los brasileños, el nombre -sin duda, fundamental- de Guimarães Rosa ${ }^{23}$. Más allá de la distinción entre

have always been too shy in the presence of national literatures, too diplomatic: as if one had English, American, German literature — and then, next door, a sort of little parallel universe where comparatists studied a second set of literatures, trying not to disturb the first set. No; the universe is the same, the literatures are the same, we just look at them from a different viewpoint; and you become a comparatist for a very simple reason: because you are convinced that that viewpoint is better. It has greater explanatory power; it's conceptually more elegant; it avoids that ugly 'one-sidedness and narrow-mindedness'; whatever. The point is that there is no other justification for the study of world literature (and for the existence of departments of comparative literature) but this: to be a thorn in the side, a permanent intellectual challenge to national literatures-especially the local literature. If comparative literature is not this, it's nothing. Nothing. 'Don't delude yourself', writes Stendhal of his favourite character: 'for you, there is no middle road.' The same is true for us" (MORETTI, 2000).

22 "Asked about his intellectual masters in an interview from 1985, Agamben spoke of both Heidegger and José Bergamín, noting that during their lifetimes he thought of them as "examples and as friends" and that "only after their deaths did I come to think of them as masters [maestri]" (DE LA DURANTAYE, 2009, p. 395). Pueden consultarse también las páginas que Agamben le dedica en Autoritratto nello studio (2017, pp. 54-63). El tópico del reloj sirve así en Espańa para acusar de mero anacronismo a un autor eminentemente heterocrónico-y, con él, a una parte importante de escritores exiliados (ARANGUREN, 1953).

23 Casanova se refiere al concepto de "literariedad" (2001, p. 32) de Jakobson. Y, en la sección "El meridiano de Greenwich o el tiempo literario", habla de la "distancia estética": "La distancia estética se mide [...] en términos temporales: el meridiano de origen instituye el presente, es decir, en el orden de 
prosa y poesía, sobre la que convendría volver, podemos pensar que uno de los motivos de esa exclusión es que tanto Casanova (respecto a la literatura brasileña) como Moretti (respecto a la literatura en general) tienen como referencia, respectivamente, la obra de Candido ${ }^{24}$ y de Schwarz ${ }^{25}$, quienes construyen una imagen de la literatura, y de la literatura brasileńa, muy diferente a la de Haroldo, quien publica el Sequestro do barroco precisamente para revertir esta situación. Sea como sea, el caso -y se trata propiamente de un caso, como el de Gregorio de Matos para Haroldo- es que en esa República de las Letras -que, tal como ocurre con nuestras democracias, se sostiene en lo que excluye, produciendo un resto-, por su propia policía y legislación, no se menciona uno de los promotores más importantes de la vanguardia crítica y literaria brasileña, un autor que justamente se apoya en Goethe y en su idea de la Weltliteratur para construir su proyecto crítico y poético $^{26}$. Y en tal caso podemos preguntarnos no solo por las políticas de la literatura, sino también por las políticas de la crítica: no solo ni principalmente por el objeto de estudio, sino también y principalmente por la función y el funcionamiento de esas historias.

La torsión americana, el pliegue barroco, el desplazamiento deconstructivo

"O boom, fenômeno recente e epidérmico, ao nivel dos mass-media serviu [...] de alerta assombrado e aviso aos navegantes incautos, para com a turbulência larvada e explosiva de uma nova relação dialógica que se vinha desenvolvendo sub-repticiamente, escamoteada pela suficiência monolíngue dos usuários de línguas "imperiais" (como o francês, cada vez menos, e o inglês, cada vez mais), uma relação que estava minando e corroendo as bases da koiné literária predefinida em termos de literaturas "mais velhas" e "maiores", de "troncos", "galhos principais" $e$ "esgalhos secundários".

De Campos, 1981a, p. 253.

la creación literaria, la modernidad" (p. 123). Y después: "La única manera, en el espacio literario, de ser verdaderamente moderno, es oponerse al presente como superado, mediante un presente más presente" (p. 126). Aquí aparece, sin llegar a ser presentado como problema, el problema de la contemporaneidad.

24 Casanova presenta a Candido como un "gran crítico, empeñado en evaluar de nuevo la literatura de su país" y, sin embargo, "víctima de este ostracisme estructural" (CASANOVA, 2001, p. 360) inherente a la República mundial de las Letras.

25 Cf. las referencias de Moretti (2002) a Schwarz.

26 Haroldo abre y cierra su texto sobre la razón antropofágica remitiendo a ese concepto heredero de Goethe (1981a, p. 233 y 255), al cual también se refiere implícitamente como apropiación cuando se ocupa de la plagiotropia (1981b, p. 75-76). 
Santiago señala 1970 - una fecha, escribe, "que não é precisa; serve antes de baliza" - como un momento de transición en el cual comienzan a emerger en Brasil una serie de perspectivas teóricas que desbordan el planteamiento literario de Antonio Candido (SANTIAGO, 1994, p. 19) ${ }^{27}$. Esas modalizaciones de la literatura, sostenidas por algunos de sus discípulos -Haroldo, Leyla Perrone, Luiz Costa-Lima-, desplazan y problematizan los modelos de pensamiento recibidos a través de la incorporación de las nuevas perspectivas teóricas. Con Haroldo y con Santiago, puede hablarse de la incorporación de una torsión americana que se hace legible desde los desplazamientos llevados a cabo por la deconstrucción.

De ese modo, lo que en Candido y en Casanova era una falta, un retraso o una deuda, va a ser pensado, desde la perspectiva que construyen Santiago en "O entre-lugar do discurso latino-americano" y Haroldo en "Da razão antropofágica: diálogo e diferença na cultura brasileira" como la singularidad de una torsión americana. Si el modelo del sociólogo francés se construía a partir de la contraposición Francia/Alemania, este aparece bajo la contraposición diferencial Latinoamérica/Europa. Su perspectiva, a diferencia del modelo comunicativo y enraízado de Candido, es nietzscheana y derrideana. En el origen no están ya el habla y la razón, sino la escritura y la discordia. "A vitória do branco no Novo Mundo", escribía Santiago, "se deve menos a razóes de caráter cultural, do que ao uso arbitrário da violência e à imposição brutal de uma ideologia” (2013, p. 13).

Sus textos están marcados por el desplazamiento: Santiago presenta su conferencia en 1971, significativamente, en la Université de Montréal (Québec), en francés ${ }^{28}$, en un encuentro en compañía de René Girard y Michel Foucault. Publicado en inglés en 1973 con el título "The LatinAmerican Litterature: the Space in-between”, no se publicó en portugués, en Brasil, hasta 1978, en Uma literatura nos trópicos. El texto de Haroldo, por su parte, es una conferencia impartida en 1980 en Lisboa que será publicada en Portugal 1981 y en 1983 en Brasil.

En su conferencia, Santiago trabaja con un corpus casi exclusivamente francés, con la excepción de Oswald de Andrade, Cortázar (que refiere a un personaje latinoamericano en un restaurante de París) y Borges (y su francés

27 Según Santiago, ese giro "anuncia o fim do seu [de Candido] horizonte de atuação como mediador entre obra e público" y "a incapacidade [...] que ele experimenta de continuar a dialogar, apaixonadamente, com obras escritas depois dos anos 70" (1994, p. 20).

28 Como ha seńalado el propio Santiago, Eugenio Donato, quien le invitó al evento, "achou o título enigmático, tendo sugerido um outro: "Naissance du sauvage, Anthropofagie Culturelle et la Littérature du Nouveau Monde" (2013, p. 30). En una entrevista realizada en 2011 declaraba Santiago respecto al texto: "Lo escribí pensando mucho en Montreal pues Canadá, en aquel momento, estaba dividido entre el inglés y el francés: el inglés maravillosamente bien desde el punto de vista económico y el francés desde el punto de vista cultural. Por lo tanto, había esta confluencia problemática y la necesidad de pensar (también allá) el entre-lugar, donde las dos fuerzas pudieran convergir...” (RAMOS, 2012, p. 189). 
Pierre Menard), pero no de Marx, que es leído por mediación de Althusser. Ahí Santiago se pregunta por "o lugar que ocupa hoje o discurso literário latino-americano no confronto com o europeu" (2013, p. 10) y, para hacerlo, alude al fragmento en el que Montaigne refiere a la sorpresa del rey Pirro ante la disposición militar de los bárbaros a los que se enfrentaba: "Je ne sçay, dit-il, quels barbares sont ceux-ci (car les Grec appelloyent ainsi toutes les nations estrangieres), mais la disposition de cette armée que je voy n'est aucunement barbare" (MONTAIGNE, 1962, p. 230-231). Ese fragmento, que abre, significativamente, el capítulo que Montaigne dedica a los caníbales de Brasil, indica que los bárbaros no se comportan como tales, planteando un juego de temporalidades desplazadas.

La guerra y la antropofagia son los dos paradigmas que estructuran la propuesta de Santiago, en la cual se anuncia -haciendo una analogía con la antigua civilización griega y la nueva barbarie romana- el discurso latinoamericano, en tanto que entre-lugar, como discurso por-venir. "A maior contribuição da América Latina para a cultura ocidental vem", anuncia Santiago, "da destruição sistemática dos conceitos de unidade e de pureza" (2013, p. 18). El diagnóstico y el programa de Santiago es conocido:

A América Latina institui seu lugar no mapa da civilizaçáo ocidental graças ao movimento de desvio da norma, ativo e destruidor, que transfigura os elementos feitos e imutáveis que os europeus exportavam para o Novo Mundo. Em virtude do fato de que a América Latina não pode mais fechar suas portas à invasão estrangeira, não pode tampouco reencontrar sua condição de "paraíso", de isolamento e de inocência, constata-se com cinismo que, sem essa contribuição, seu produto seria mera cópia-silêncio-, uma cópia muitas vezes fora de moda, por causa desse retrocesso imperceptível no tempo, de que fala Lévi-Strauss. Sua geografia deve ser uma geografia de assimilação e de agressividade, de aprendizagem e de reação, de falsa obediência. A passividade reduziria seu papel efetivo ao desaparecimento por analogia. Guardando seu lugar na segunda fila, é, no entanto, preciso que assinale sua diferença, marque sua presença, uma presença muitas vezes de vanguarda (p. 19).

El mestizaje reivindicado por Santiago, que le permite criticar la antropología de Tristes trópicos, en la que "o híbrido é o mais terrível dos monstros" (2005, p. 39), encuentra en la teoría de la textualidad derridiana y, particularmente, en las primeras páginas de $S / Z$ (1970) de Barthes -que plantean el problema de la evaluación y construyen una tipología que distingue entre textos meramente legibles y textos escribibles (SANTIAGO, 2013, p. 22)-, un modo de pensar la diferencia latino-americana.

Haroldo retoma esa misma cuestión en "Da razão antropofágica...”. Lo que separa su planteamiento del de Paz tiene que ver, como hemos indicado anteriormente, con esa inflexión introducida por Santiago y que se ampara en 
el modernismo de Oswald de Andrade. El nacionalismo modal ("o nacionalismo como movimento dialógico da diferença") al que se refiere Haroldo en este contexto sería una posible respuesta tanto al cosmopolitismo universalista como al nacionalismo ontológico "como unção platônica da origen e rasoura acomodatícia do mesmo” (DE CAMPOS, 1981a, p. 237) ${ }^{29}$.

\section{El secuestro del Barroco en la República mundial de las Letras}

"Que le droit à "délirer" a été conquis par la littérature depuis Lautréamont au moins et que la critique pourrait fort bien entrer en délire selon des motifs poétiques, pour peu qu'elle le déclarât; enfin parce que les délires d'aujourd'hui sont parfois les vérités de demain".

BARTHES, 1966, p. 793

A la luz de Santiago y de Haroldo, se observa cómo el modelo de Candido y el de Bourdieu presentan una analogía de fondo ${ }^{30}$. O sequestro do barroco de Haroldo adquiere, así, consecuencias inesperadas. Ese título, ligeramente desplazado, sería apropiado, y con más motivos, para la propia Francia. Las implicaciones de ese secuestro -que hacían a Barthes definir la verosimilitud crítica francesa de 1965 en términos de claridad, buen gusto y objetividad (BARTHES, 1966) - hacen de lo barroco uno de los grandes Otros de la tradición francesa ("mais rendre la lumière", escribía Paul Válery

29 "Na verdade, o que ocorria, aqui, era a mudança radical do registro dialógico. Ao invés da velha questão de influências, em termos de autores e obras, abria-se um novo processo: autores de uma literatura supostamente periférica subitamente se apropriavam do total do código, reivindicavam-no como patrimônio seu, como um botim vacante à espera de um novo sujeito histórico, para remeditar-lhe o funcionamento em termos de uma poética generalizada e radical, de que o caso brasileiro passava a ser a óptica diferenciadora e a condiçấo de possibilidades. A diferença podia agora pensar-se como fundadora" (DE CAMPOS, 1981a, p. 246-247).

30 Antelo se ha referido recientemente al uso que hace Candido del término estrutura estructurante, conectando a ambos autores: "Pode haver aí uma parcial cumplicidade compartilhada com Pareyson, autor a quem Candido não cita, embora não necessariamente com seu discípulo, Umberto Eco, quem também se apropria do conceito e a quem, de fato, se refere. Mas, a meu ver, a proveniência mais provável para essa noçáo é a de um althusseriano (um aristotélico) como Pierre Bourdieu, que lançara mão do conceito, também em 1973, pouco antes de eu ouvi-lo no curso de Candido. A partir da tradiçấo neokantiana de Humboldt e Cassirer, que na linguística norte-americana se perpetuava com Sapir e Whorf, e a seguir com Durkheim, as formas deixam de ser universais e, portanto, transcendentes, para serem, com Panofsky, contingentes e sociais, de tal sorte que a objetividade do sentido mede-se pela concordância de subjetividades estruturantes, conforme o esquema senso=consenso. Com efeito, a estrutura estruturante, tal como o habitus de Bourdieu, generaliza a noção de esquema e é conceito constituído a partir da combinação de paradigmas de percepção, avaliação e pensamento que, no caso de Candido, eram voltados, claramente, para a verdade, entendida como praxis. Graças a essa gramática geral das práticas, a língua não era mais vista como um objeto construído e acabado, com regras que funcionassem por si próprias, mas passava a ser considerada uma estrutura sensível à sociedade que constrói tais convençóes, modificaas e, chegado o caso, as destrói, de tal sorte que a língua é tanto uma estrutura estruturada, quanto uma estrutura estruturante" (ANTELO, 2018, p. 452-453). 
en Le cimetière marin, "suppose d'ombre une morne moitié"). Ese barroco habría entrado en Francia, si hacemos caso a los planteamientos de Haroldo, de la mano del cubano Severo Sarduy, que habría barroquizado Tel Quel:

Una influencia que no está bien caracterizada es la presencia de Severo Sarduy en el grupo Tel Quel. Si es verdad que Sarduy recibió del grupo Tel Quel, incluso a nivel teórico, un bagaje metalingüístico que él no tenía antes para enfrentarse teóricamente con problemas de intertextualidad, etc., no es menos cierto que él ha sido la persona que en la revista escribió por primera vez sobre Góngora. Se puede decir que barroquizó a Tel Quel, que era un grupo muy cartesiano, muy valeryano. Y Valéry es el clásico de Mallarmé [...]. La barroquización que se puede hoy verificar en un texto como Paradis de Sollers (que es muy reciente, por ejemplo, en relación a mis Galaxias, que empiezan en 1963, mientras Solleres sólo en 1972 inicia la publicación de su texto "paradisíaco") nos hace pensar que si la Kristeva bajtinizó a Severo Sarduy, él a su vez barroquizó a Tel Quel. Y mis Galaxias, publicadas fragmentariamente en la revista rival Change, en versión francesa, en 1970, contribuyeron sin duda a esta solerte "perversión" del logos cartesiano. Las cuentas están hechas, y la América barroca está ahí. Y esto significa también la congenialidad de lo barroco latinoamericano, que tiene arcamente que ver con Góngora y Quevedo, y con toda esa tradición de proliferación del significante, y modernamente con la revolución de la palabra joyceana" (ORTEGA, 1985, p. 29; 2010, p. 67) ${ }^{31}$.

Haroldo habla en sus Depoimentos de oficina, en que repasa su propia trayectoria poética e intelectual, de una estrategia de apropiación basada en las "anticipaciones". Ese registro, en el que Haroldo trabajó de modo militante, desquicia las cronologías y los órdenes de prioridad en nombre de una reformulación específica al servicio de la creación. Sostiene ahí Haroldo:

O Movimento da Poesia Concreta foi, sobretudo (e reconhecidamente) um movimento antecipatório. O elogio que me fez Derrida, na homenagem que recebi nos 50 anos de fundação da PUC-SP, não foi meramente formal, gratuito. Fundamenta-se no que ele conhecia do meu trabalho de poeta, de tradutor e de teórico. Antes daquela declaração, de que ele estava chegando onde eu já me encontrava, eu o tinha visto e conversado com ele poucas vezes, em Paris e em Veneza, ou quando passou rapidamente por São Paulo, num jantar na casa da amiga e notável crítica literária Leyla Perrone-Moisés. No artigo de 1955, em que me ocupei da questão da "obra de arte aberta", não apenas prefiguro em vários anos a Opera aperta de Umberto Eco (ele expressa e generosamente o reconhece no prólogo à edição brasileira do seu livro), como

31 Con relación a las referencias de Haroldo a Paradis y a la polémica entre Tel quel y Change, cf. Hidalgo Nácher, 2019. 
termino por falar de um "barroco moderno" ou "neobarroco", antecipandome ao querido amigo e admirável escritor (prosador, poeta, ensaísta) Severo Sarduy. Até mesmo o conceito de transculturação, que Angel Rama retoma em 1983 (Transculturación narrativa em América Latina) e 1984 (La ciudad letrada), a partir do antropólogo e africanista cubano Fernando Ortiz (Los factores humanos de la cubanidad, 1940), já havia sido por mim desenvolvido na "Nota Prévia" a meu livro A operação de texto (1976), onde estava ligado à idéia de "tradução criativa" ou "transcrição" (2001, p. 94-95).

La anticipación no es un movimiento de reconocimiento de algo dado, sino -en la lógica borgeana de "Kafka y sus precursores"- una fundación en el presente siguiendo la lógica paradójica de una historia sincrónica, sobre la que Haroldo ya había reflexionado en dos textos de 1967 ("Poética sincrónica” y “Texto e História”) y sobre la que, introduciendo modulaciones y desplazamientos, no dejaría de reflexionar.

No importa, en ese sentido, que Haroldo convierta un homenaje en una prueba. Así, cuando afirma: "Não é à toa que o Derrida escreveu aquele depoimento em minha homenagem dizendo que ele estava chegando onde eu já me encontrava. Ele não fez elogio gratuito e eu nem sequer sou amigo dele" 32 (p. 94). Tampoco importa, por otro lado, que Eco escribiera un libro y Haroldo simplemente un artículo de periódico (DE CAMPOS, 1955). "Essa defesa de uma obra aberta em literatura", sostiene Haroldo, "foi escrita vários anos antes do livro de Umberto Eco. No prefácio da edição brasileira de Obra Aberta (São Paulo, Perspectiva, 1968), o teórico italiano reconheceu com elegância esse evento precursor" (p. 33). Ese gesto crítico, más allá de la literalidad de los contenidos - a veces pertinente, dudosa en otros casos-, puede entenderse como una respuesta muchas veces arbitraria, pero estratégica, a la arbitrariedad naturalizada del registro hegemónico. Ya el propio Eco, que como se ve en la cita de arriba se prestó, antes que Derrida, al juego de las anticipaciones en el prólogo de la traducción de Opera aberta al portugués, llamó a Haroldo, irónicamente, "plagiário profético"33.

Lo que en Haroldo era, por encima de todo, un gesto, en el libro Lautréamont austral (1984), de Leyla Perrone y Emir Rodríguez Monegal, asume la forma de una tesis historiográfica basada en los protocolos de la

32 Derrida, quien lo presenta en ese texto de 1996 como uno de sus "grands-amis-admirables" -al cual, sin embargo, solo ha visto dos veces-, escribió: "Dans l'horizon de la littérature, et avant tout dans l'intimité de la langue des langues, chaque fois tant de langues dans toute langue, je sais que Haroldo y aura eu accès comme moi avant moi, mieux que moi. C'est-à-dire qu'il m’attendait pourtant, déjà, de l'autre côté, arrivé avant moi le premier, sur l'autre rive" (2015, p. 18).

33 "A Haroldo plagiário profético Umberto Milan 20.3.91" (Umberto Eco, Lo strano caso della Hanau 1609, Milano, Bompiani, 1989; Acervo Haroldo de Campos, tombo 11026). Conviene no perder de vista las reflexiones de Haroldo sobre el "movimiento plagiotrópico da literatura" recogidas en Deus e o Diabo no Fausto de Goethe (1981b, p. 75), en las que remite explicitamente a la semiosis ilimitada de Eco. 
disciplina. A través de las lecturas españolas de Isidoro Ducasse, más conocido como el conde de Lautréamont, Leyla Perrone y Emir Rodríguez Monegal plantearon en ese libro el problema de la americanidad de Lautréamont, quien no sería un autor francés, sino uruguayo.

El libro es un brillante y riguroso estudio de las consecuencias de la americanidad de Lautréamont en su escritura. Los autores, volviéndose sobre algo que estaba demasiado a la vista para ser notado, mostraban la importancia de una Iliada espańola, en traducción de José Gómez de Hermosilla, que Lautréamont tenía en su biblioteca; destacaban los posibles rastros del cerco de Montevideo en la vida y en la escritura del autor; reflexionaban sobre su incorporación de un barroco al que fue profundamente resistente la tradición francesa, por la mediación de una traducción española del Arte de hablar, obra también de Hermosilla; destacaban la relación de exterioridad de Lautréamont con la lengua francesa, que pasaba también por el euskera del sur de Francia. Con su trabajo (por el cual "dois pontos importantes da crítica de Lautréamont ficam confirmados, e ao mesmo tempo deslocados: a questão da influência de Homero e o papel da retórica em sua obra" [PERRONE-MOISÉS y RODRÍGUEZ MONEGAL, 2014, p. 18]), los autores aislaban en los orígenes de la vanguardia francesa una veta americana que es, por mediación hispánica, una veta barroca.

Ahora bien, sus contribuciones, treinta y cinco años después, todavía no han sido incorporadas a la crítica especializada (PERRONE-MOISÉS, 2019). La división del trabajo -asociada a la visibilidad de los espacios y a la posibilidad de quién puede hablar e intervenir sobre qué- se aprecia aquí, tal como, por lo demás, Monegal, mediador de las literaturas latinoamericanas desde Gallimard (donde hizo de lector y recomendó libros para las colecciones "La Croix du Sud" y "Du Monde Entier" [GRAS, inédito]), no podía intervenir en los debates sobre un autor "francés", más cuando esa francesidad del autor era puesta entre comillas para conectarlo con problemas que excedían los debates centrípetos.

Ya Severo Sarduy recordó, respecto a Lautréamont, que "l'autre est á Mont(évideo)" (1986, p. 117). Ahora bien, como escribía Leyla Perrone respecto a ese secuestro, "os franceses eran renitentes em devolver Lautréamont ao Uruguai” (1995, p. 10) -resistentes a pensarlo en relación con un exceso que será tomado como un absceso insignificante.

La historia del libro, que en este mismo dossier narra Leyla Perrone, es significativa: fue rechazado por las editoriales francesas hasta que, en 2001, fue publicado por L'Harmattan. Lautréamont austral sufrió, y todavía hoy sufre, una resistencia activa por parte de la crítica lautreamoniana y sus descubrimientos críticos no son movilizados en la última edición de las obras de Lautréamont en La Pléiade. De ese modo, el olvido literario de Lautréamont se repite y se redobla en su olvido crítico. Ese trabajo y la reconstrucción del destino editorial y crítico 
de su libro muestran que esos olvidos no parten de una simple ingenuidad o ignorancia, sino que son interesados - pues tener en cuenta esas apreciaciones empíricas obligaría a revisar los propios criterios teóricos e historiográficos.

\section{Modelos y problemas}

Lo expuesto hasta ahora muestra la dificultad de reducir a modelos teóricos la singularidad de los textos y sus contextos y hace palpable que no es posible leer lo nacional al margen de aquello que lo excede ni reducir ese exceso y sus múltiples sobredeterminaciones a un solo relato y a una única cronología. La imaginación crítica, por poco que se deje afectar por esos nuevos corpus que recorta, descubre a cada paso relaciones inusitadas que no han quedado registradas - $\mathrm{O}$, como en el caso Lautréamont, han sido tomadas como meros datos externos- porque no se ajustan a los parámetros establecidos. El antropólogo Eduardo Viveiros de Castro -que aloja el pensamiento amerindio, que ha contribuido en gran medida a teorizar, en el origen de nada más y nada menos que la antropología estructural de Lévi-Strauss ${ }^{34}-$, diferenciaba, en una entrevista recogida en $A$ inconstância da alma selvagem, entre antropología y sociología del siguiente modo:

A antropologia se distingue na medida em que ela presta atenção ao que as outras sociedades têm a dizer sobre as relaçôes sociais, e não, simplesmente, parte do que a nossa tem a dizer e tenta ver como é que isso funciona lá [...]. Para mim, se há alguma diferença entre antropologia e sociologia, seria esta: o objeto do discurso antropológico tende a estar no mesmo plano epistemológico que o sujeito desse discurso (VIVEIROS DE CASTRO, 2002, p. 406).

Las perspectivas dominantes sobre la literatura mundial se inscriben en una visión sociológica, en el sentido específico que da Viveiros de Castro a este término -y que se refiere a una mirada que no se deja afectar por la singularidad de su objeto, sino que lo interpreta a partir de categorías preestablecidas-, el cual, sin embargo, no tenemos por qué atribuir al conjunto de la sociología.

Cabe tomar esa distinción y llevarla a nuestra experiencia teórica y literaria estableciendo una diferencia operativa análoga entre la teoría de la literatura y la teoría literaria (COMPAGNON, 1998, p. 23). La teoría de la literatura hace de la literatura un objeto y -distanciándose de ella- aspira a la universalidad; la teoría literaria, en cambio, está siempre afectada por

34 "Lévi-Strauss é o momento em que o pensamento ameríndio faz seu lance de dados: graças a seu grande mediador conceitual, esse pensamento ultrapassa seu próprio "contexto" e se mostra capaz de dar a pensar a outrem, isto é, a todo aquele que, persa ou francês, se disponha, sem mais, a simplesmente pensar" (VIVEIROS DE CASTRO, 2009, p. 234). 
la práctica o la experiencia de una lectura que no es ni simplemente una proyección de un saber previo ni el reconocimiento de una universalidad. La teoría literaria es, así, en parte, una prolongación de la propia literatura y, como decía Derrida en una entrevista en 1989, no habla simplemente "sobre" la literatura, sino tal vez "con", "hacia", "para", "en contra de", "en camino hacia”... la literatura (2017, p. 122). Eso hace que la teoría no sea aplicable y que la literatura no sea ejemplar. Y permite ver, por contraste, para qué sirven los modelos.

\section{Bibliografía}

AGAMBEN, Giorgio. ¿Qué es lo contemporáneo. Desnudez. Buenos Aires: Adriana Hidalgo, 2011, p. 17-29.

AGUILAR, Gonzalo. Construir el pasado (algunos problemas de la Historia de la Literatura a partir del debate entre Antonio Candido y Haroldo de Campos). Poesía concreta brasileña: las vanguardias en la encrucijada modernista. Buenos Aires: Beatriz Viterbo, 2003, p. 381-404.

ANTELO, Raúl. Maria com Marcel. Duchamp nos trópicos. Belo Horizonte: UFMG, 2010.

ANTELO, Raúl. Mais-valia crioula: estruturada, porém, estruturante. In: FONSECA, Maria Augusta; SCHWARZ, Roberto (orgs.). Antonio Candido 100 Anos. São Paulo: Editora 34, 2018, p. 442-455.

ARANGUREN, José Luis López. La evolución espiritual de los intelectuales españoles en la emigración. Cuadernos Hispanoamericanos, n. 38, p. 123-157, 1953.

BARTHES, Roland. Critique et vérité. In: CEuvres complètes II. Paris : Seuil, 2002 [1966].

BARTHES, Roland. S/Z. In: CEuvres complètes III. Paris: Seuil, 2002 [1970].

BOURDIEU, Pierre. Les conditions sociales de la circulation internationale des idées. Actes de la Recherche en Sciences Sociales, n. 145, 2002a [1989].

BOURDIEU, Pierre. La domination masculine. Paris: Seuil, 2002b.

BOURDIEU, Pierre. Lección sobre la lección. Barcelona: Anagrama, 2002c (lección inaugural de 1982).

BOURDIEU, Pierre. Todo es social. Entrevista de Pierre-Marc de Biasi a Pierre Bourdieu. In: Diana Sanz Roig (ed.). Bourdieu después de Bourdieu. Madrid: Arco/Libros, 2014, p. 51-68. 
BUTOR, Michel; LAUNAY, Michel. Résistances. Conversation aux antipodes. Paris: PUF, 1983. Citado de ROGER, Thierry (tesis doctoral). L'archive du Coup de dés. Étude critique de la réception de Un Coup de Dés jamais n'abolira le Hasard de Stéphane Mallarmé (1897-2007). Paris IV-Sorbonne, 2008 [online: http://www. theses.paris-sorbonne.fr/these.thierry.roger.pdf (consultado: 1 de febrero de 2019)].

CANDIDO, Antonio. Formação da literatura brasileira (momentos decisivos). Vol. I: 1750-1836). 3a ed. São Paulo: Martins, 1969.

CASANOVA, Pascale. La República mundial de las Letras. Madrid: Anagrama, 2001.

CATELLI, Nora. La cuestión americana en 'El escritor argentino y la tradición. Punto de vista, Buenos Aires, n. 77, p. 31-36, 2003.

CATELLI, Nora. Juan Benet y la consagración literaria. Pensamiento literario español del siglo XX, n. 3. Zaragoza: Universidad de Zaragoza, 2009, p. 34-40.

CATELLI, Nora. Academias: los equívocos del comparatismo en el mundo (hispánico). Chuy. Revista de Estudios Literarios Latinoamericanos, n. 2, p. 34-44, 2015. Disponible en: http://www.revistasuntref.com.ar/index.php/chuy/article/view/119.

CATELLI, Nora. Asimetría : espectros del comparatismo en la circulación de la teoría. Badebec, v. 8, n. 15, p. 179-198, 2018.

CHIAPPINI, Ligia. Poesia concreta, Haroldo de Campos e a formaçao da literatura brasileira. In: WROBEL, Jasmin (org.). Roteiros de palabras, sons, imagens. Os diálogos transcriativos de Haroldo de Campos. Frankfurt and Main: TFM, 2018, p. 39-56.

COMPAGNON, Antoine. Le démon de la théorie. Littérature et sens commun. Paris: Seuil, 2001 [1998].

COTA, Débora. Em trans: leituras latino-americanas do presente. In: SCRAMIM, Susana. (org.). O contemporâneo na crítica literária. São Paulo: Iluminuras, 2012, p. 141-162.

DALMARONI, Miguel. Historia literaria y corpus crítico (aproximaciones williamsianas y un caso argentino. Boletin del Centro de Estudios de Teoría y Critica Literaria, n. 12, diciembre 2005.

DALMARONI, Miguel. Hasta que la muerte las separe. Crítica literaria y teoría en la Argentina (algunas notas). El taco en la brea, año 5, n. 8, p. 101-109, 2018.

DAMROSCH, David. What is World Literature?. Princeton: Princeton University Press, 2003.

DE CAMPOS, Haroldo. A Obra de Arte Aberta. Diário de São Paulo, 3 de julio de 1955. 
DE CAMPOS, Haroldo. Texto e História. A ReOperação do texto. São Paulo: Perspectiva, 2013 [1967], p. 15-25.

DE CAMPOS, Haroldo. Da razão antropofágica: diálogo e diferença na cultura brasileira. Metalinguagem \& outras metas. São Paulo: Perspectiva, 2006 (1992). [El texto, fechado en 1980, se publicó en la revista Colóquio/Letras (Lisboa, Fundação Calouste Gulbeklan), n. 62, en julio de 1981. Y en el Boletim Bibliográfico Biblioteca Mário de Andrade, São Paulo, v. 44, jan./dez. 1983]. 1981a, p. 231-255

DE CAMPOS, Haroldo. Deus e o Diabo no Fausto de Goethe. São Paulo: Perspectiva, 2008 [1981b].

DE CAMPOS, Haroldo. O sequestro do barroco na formação da literatura brasileira: o caso Gregório de Matos. São Paulo: Iluminuras, 2011.

DE CAMPOS, Haroldo. Semiótica como prática e não como escolástica. Depoimentos de oficina. São Paulo: Dobradura, 2018 [2001], p. 71-99

DE DIEGO, José Luis. ¿Quién de nosotros escribirá el Facundo? Intelectuales y escritores en Argentina (1970-1986). La Plata: Al Margen, 2001.

DE LA DURANTAYE, Leland. Giorgio Agamben: a critical introduction. Standford : Standford University Press, 2009.

DERRIDA, Jacques. "Chaque fois, c'est-à-dire, et pourtant, Haroldo...” (p. 16-18), Cisma, edição especial Haroldo de Campos, año IV, 2015.

EVEN-ZOHAR, Itamar. La posición de la literatura traducida en el polisistema literario. Traducción de Montserrat Iglesias Santos revisada por el autor. In: Teoría de los Polisistemas, Estudio introductorio, compilación de textos y bibliografía por Montserrat Iglesias Santos. Madrid: Arco, 1999.

GERBAUDO, Analía. How Does Literary Theory Cross Boundaries (or Not)? Notes on a Case Study. Journal of World Literature, n. 3, p. 92-103, 2017.

GERBAUDO, Analía. El fuego, el agua, la biodegradabilidad. Apuntes metodológicos para un archivo por-venir. In: VIGNA, Diego y OLGA ARÁN, Pampa. Archivos, artes y medios digitales: teoría y práctica. Córdoba: Centro de Estudios Avanzados / Universidad Nacional de Córdoba, 2018, p. 41-66

GERBAUDO, Analía. La institucionaliación de las Letras en la universidad argentina (1945-2010). Notas "en borrador" a partir de un primer relevamiento. Santa Fe: UNL (en línea), 2014. <htttp://www.fjuc.unl.edu.ar/centros/cedintel/interco_vf.pdf>. Consultado el 2 de febrero de 2019:

GRAMUGLIO, María Teresa. Literatura mundial. Una aproximación. Nacionalismo y cosmopolitismo en la literatura argentina. Rosario: Editorial Municipal de Rosario, 2013, p. 383-393 
GRAS, Dunia. Transatlantic Literary Networks during the Cold War: Emir Rodríguez Monegal, Reader for Gallimard. (inédito).

HEILBRON, Johan. Towards a Sociology of Translation. Book Translations as a Cultural World-System, European Journal of Social Theory, v. 4, n.2, p. 429-44, 1999.

HIDALGO NÁCHER, Max. De una España peregrina a una España fantasmal: las imposibles vueltas de José Bergamín. In: AA. VV. El exilio republicano de 1939. Viajes y retornos. Sevilla: Renacimiento, 2014a, p. 626-637.

HIDALGO NÁCHER, Max. Los límites del teatro de José Bergamín y el exilio como contra-tiempo. Revista Chilena de Literatura, n, 87, p. 161-179, $2014 \mathrm{~b}$.

HIDALGO NÁCHER, Max. La Teoría de la Literatura: pasado y presente de un problema. Badebec, v. 7, n, 13, p. 188-211, 2017.

HIDALGO NÁCHER, Max. Fábulas del país de Jaula / El porvenir de la literatura. Quimera, Barcelona, n. 411, p. 16-25, 2018.

HIDALGO NÁCHER, Max, Redes intelectuais e constelaçóes textuais: a biblioteca de Haroldo de Campos como espaço de crítica e de criação. in: Circuladô, São Paulo, 2019.

MICELI, Sergio. Sonhos da periferia. Inteligência argentina e mecenato privado. São Paulo: Todavia, 2018.

MONTAIGNE, Michel de. Livre I. Chapitre XXXI. Des cannibales. In: Essais. Tome I. Paris :Garnier Frères, 1962.

MORETTI, Franco. Conjectures on World Literature. New Left Review, n. 1, enero-febrero 2000.

MORETTI, Franco. More conjectures. New Left Review, n. 20, marzo-abril 2003.

ORTEGA, Julio. Conversación con Haroldo de Campos, Syntaxis, La Laguna, n. 8-9, p. 15-32, 1985. [Haroldo retoma esta entrevista en "Tres (re)inscriçôes para Severo Sarduy” (p. 63-74) (1995). O segundo arco-iris branco. Sáo Paulo: Iluminuras, 2010].

PAZ, Octavio. Memorias y palabras. Cartas a Pere Gimferrer (1966-1997). Barcelona: Seix Barral, 1999.

PEDROSA, Célia. Crítica e grouxismo. In: ANTELO, Raúl (ed.). Antonio Candido y los estudios latinoamericanos. Pittsburgh: Universidad de Pittsburgh, 2001, p. 231-248 
PERRONE-MOISÉS, Leyla. Vira e mexe nacionalismo. Paradoxos do nacionalismo literário. São Paulo: Companhia das Letras, 2007.

PERRONE-MOISÉS, Leyla. Prólogo à edição uruguaia. In: PERRONE-MOISÉS, Leyla; RODRÍGUEZ MONEGAL, Emir. Lautréamont austral. São Paulo: Iluminuras, 2014 [1995], p. 9-11

PERRONE-MOISÉS, Leyla; RODRÍGUEZ MONEGAL, Emir. Introdução.In: PERRONE-MOISÉS, Leyla; RODRÍGUEZ MONEGAL, Emir. Lautréamont austral. São Paulo: Iluminuras, 2014 [1995], p. 15-18

PERRONE-MOISÉS, Leyla. Lautréamont Austral: Percalços de um livro. Landa, v. 7, n. 2, 2019. <https://repositorio.ufsc.br/handle/123456789/199542>.

PONTES, Heloisa. Destinos mistos. Os críticos do Grupo Clima em São Paulo (194068). São Paulo: Companhia das Letras, 1998.

PUCHEU, Alberto. Uma tese sobre a crítica literária brasileira. In: SCRAMIM, Susana. (org.). O contemporâneo na crítica literária. Sáo Paulo, Iluminuras, 2012, p. 87-114.

PUXAN-OLIVA, Marta; MIRIZIO, Annalisa (eds.). Rethinking World Literature Studies in Latin American and Spanish Contexts. Journal of World Literature, v. 2, n.1, p. 1-9, 2017.

RAMOS, Julio. Los viajes de Silviano Santiago. Conversación con Julio Ramos. Zama, n.4, p. 185-196, 2012.

ROSA, Nicolás. Sur o el espíritu de la letra. La letra argentina (crítica 1970-2002). Buenos Aires: Santiago Arcos, 2003 [1971], p. 73-82.

SANTIAGO, Silviano. Préfacio. In: PEDROSA, Celia. Antônio Candido: a palavra empenhada. São Paulo: EDUSP, 1994, p.15-23.

SANTIAGO, Silviano. A viagem de Lévi-Strauss aos trópicos / Democratização do Brasil 1979-1982 (Cultura versus arte). Brasília: Instituto Rio Branco, 2005.

SANTIAGO, Silviano. "O entre-lugar do discurso latino-americano". Uma literatura nos trópicos. São Paulo: Perspectiva, 1978. Citado de SANTIAGO, Silviano. "O entre-lugar do discurso latino-americano” Ensaios antológicos. São Paulo: Nova Alexandria, 2013, p. 10-30.

SAPIRO, Gisèle, Globalization and Cultural Diversity in the Book Market. The case of literary translations in the US and in France. Poetics, n. 38, p. 419-439, 2010.

SARDUY, Severo. Lautréamont e o barroco. [1986]. In: PERRONE-MOISÉS, Leyla y RODRÍGUEZ MONEGAL, Emir. Lautréamont austral. São Paulo: Iluminuras, 2014, p. 117-124. 
SCHWARZ, Roberto. As idéias fora do lugar. In: Ao vencedor as batatas: forma literária e processo social nos inícios do romance brasileiro. São Paulo: Duas Cidades, 1977 [1972], p. 13-28.

SCHWARZ, Roberto. Saudação a Antonio Candido. In: Antonio Candido \& Roberto Schwarz. A Homenagem na Unicamp. Sáo Paulo: Unicamp, 1989.

SCHWARZ, Roberto. Um mestre na periferia do capitalismo: Machado de Assis. São Paulo: Duas Cidades, 1990.

SULLÀ, Enric. Esperant els bàrbars. 452º $F$, n. 12, p. 25-29, enero 2015. Disponible en: <https://www.452f.com/pdf/numero12/12_452f_Testimonios_orgnl.pdf>

TENÓRIO DA MOTTA, Leda. Sobre a crítica literária brasileira no último meio século. Rio de Janeiro: Imago, 2002.

VÁZQUEZ GARCÍA, Francisco. El problema de la reflexividad en Pierre Bourdieu. De la epistemología a la ética. Opinión Jurídica, Medellín, Universidad de Medellín, v. 5, n. 10, p. 87-104, julio-diciembre 2006.

VENUTI, Lawrence. Globalization. The Scandals of Translation: Towards an Ethics of Difference. London : Routledge, 1998, p. 158-189.

VIVEIROS DE CASTRO, Eduardo. Entrevista. A inconstância da alma selvagem e outros ensaios de antropologia. São Paulo: Cosac Naify, 2002, p. 395-411 .

VIVEIROS DE CASTRO, Eduardo. Metafísicas canibais. Elementos para uma antropologia pós-estrutural. São Paulo: Ubu/N-I, 2009.

Max Hidalgo Nácher. Profesor de la sección de Teoría de la Literatura y Literatura Comparada de la Universitat de Barcelona (UB) e investigador en el Grupo de Estudios del Exilio Literario (GEXEL) de la Universitat Autònoma de Barcelona (UAB). Ha realizado estancias de investigación en la Universidad de Rosario, Universidade de São Paulo, Centro de Referência Haroldo de Campos y Harvard University, y ha codirigido la revista Puentes de crítica literaria y cultural. Sus principales campos de investigación son la historia de la teoría literaria y sus usos desde la segunda mitad del siglo XX y las escrituras del exilio republicano de la guerra civil española de 1939.

E-mail: maxhidalgo@ub.edu

Recebido em: 16/01/2020 Aceito em: 31/07/2020 